\title{
MYC Is Activated by USP2a-Mediated Modulation of MicroRNAs in Prostate Cancer
}

\author{
Barbara Benassi ${ }^{1,3}$, Richard Flavin $^{4}$, Luigi Marchionni ${ }^{8}$, Silvio Zanata ${ }^{5,9}$, Yunfeng Pan ${ }^{6}$, \\ Dipanjan Chowdhury 6 , Marina Marani ${ }^{1}$, Sabrina Strano ${ }^{1}$, Paola Muti ${ }^{2}$, Giovanni Blandino ${ }^{1}$, \\ and Massimo Loda ${ }^{4,5,7,10}$
}

${ }^{1}$ Translational Oncogenomics Unit, ENEA-Casaccia, Rome, Italy ${ }^{2}$ Department of Epidemiology, Regina Elena Cancer Institute, ENEA-Casaccia, Rome, Italy ${ }^{3}$ Laboratory of Toxicology, ENEACasaccia, Rome, Italy ${ }^{4}$ Center for Molecular Oncologic Pathology Dana-Farber Cancer Institute, Harvard Medical School, Boston ${ }^{5}$ Department of Pathology and Medical Oncology, Dana-Farber Cancer Institute, Harvard Medical School, Boston ${ }^{6}$ Department of Radiation Oncology, DanaFarber Cancer Institute, Harvard Medical School, Boston ${ }^{7}$ The Broad Institute of Harvard and MIT, Cambridge, Massachusetts ${ }^{8}$ Department of Oncology, The Johns Hopkins Medical Institutions, Baltimore, Maryland ${ }^{9}$ Department of Basic Pathology and Cell Biology, Universidade Federal do Paraná Brazil ${ }^{10}$ Division of Cancer Studies, King's College, London School of Medicine, London, United Kingdom

\section{Abstract}

Ubiquitin-specific protease 2a (USP2a) is overexpressed in almost half of human prostate cancers and $c-M y c$ is amplified in one third of these tumor types. Transgenic MYC expression drives invasive adenocarcinomas in the murine prostate. We show that overexpression of USP2a downregulates a set of microRNAs that collectively increase MYC levels by MDM2 deubiquitination and subsequent p53 inactivation. By establishing MYC as a target of miR-34b/c, we demonstrate that this cluster functions as a tumor suppressor in prostate cancer cells. We identify a distinct mRNA signature that is enriched for MYC-regulated transcripts and transcription factor binding sites in USP2a overexpressing prostate cancer cells. We demonstrate that these genes are associated with an invasive phenotype in human prostate cancer and that the proliferative and invasive properties of USP2a overexpressing cells are MYC-dependent. These results highlight an unrecognized mechanism of MYC regulation in prostate cancer and suggest alternative therapeutic strategies in targeting MYC.

\section{INTRODUCTION}

The $c$-myc proto-oncogene is a transcription factor that plays a key role in regulating numerous cellular processes including metabolism, development, apoptosis, cell proliferation, and differentiation. Deregulated expression of MYC has been described in

\footnotetext{
(C) 2012 American Association for Cancer Research.

Corresponding Authors: Massimo Loda, Department of Medical Oncology, Dana Farber Cancer Institute, 450 Brookline Avenue, Boston, MA 02115. Phone: 617-632-4001; Fax: 617-632-4005; massimo_loda@dfci.harvard.edu and Giovanni Blandino, Regina Elena National Cancer Institute, Rome, Italy. blandino@ifo.it.

B. Benassi and R. Flavin share first authorship.

G. Blandino and M. Loda share senior authorship.

Note: Supplementary data for this article are available at Cancer Discovery Online (http://www.cancerdiscovery.aacrjournals.org). 
many human malignancies (including colon, breast, and prostate cancer) and plays a central role in their genesis (1). In prostate cancer, MYC seems to be a key player in disease progression and the presence of myc gene amplification (in up to $30 \%$ of cases) is associated with advanced histologic grade and worse prognosis (2). Transgenic mice expressing human MYC in the mouse prostate develop murine prostatic intraepithelial neoplasia followed by invasive adenocarcinoma and display a defined myc gene expression signature (3). Transcriptional regulation, posttranscriptional regulation, and ubiquitination appear to be important nodes in this MYC-driven network (4-8).

MicroRNAs (miRNAs) are evolutionarily conserved, endogenous, small noncoding RNAs that act as posttranscriptional regulators of gene expression. They primarily bind to the $3^{\prime}$ UTR of target transcripts leading to mRNA degradation or translational repression. Aberrant expression of miRNAs has been observed in human cancers $(9,10)$, where they can function as either tumor suppressor genes or oncogenes (11). Regulation of gene activity by miRNAs is critical to both normal cellular function and tumorigenesis. Recent studies have identified several miRNAs as regulators of MYC (12-15). Conversely, MYC regulates multiple miRNAs and causes widespread reprogramming of the miRNA network, which has been found to directly contribute to tumorigenesis $(4,6,16)$.

Deubiquitinating enzymes represent one of the largest families of enzymes responsible for regulating proteins through the ubiquitin-proteasome system (17). Specific deubiquitinating enzymes regulate the stability and function of critical cellular factors such as MYC, p53, cyclin D1, and MDM2-MDMX (7, 18-21). Ubiquitin-specific protease 2a (USP2a) is a deubiquitinating enzyme that regulates the p53 pathway by targeting MDM2 (22). It also recognizes fatty acid synthase and cyclin D1 and modulates and prevents their proteasomal degradation (21-23). USP2a is overexpressed in almost half of human prostate adenocarcinomas, enhances tumorigenicity of prostate cancer cells in vitro and in vivo, and confers resistance to apoptosis induced by chemotherapeutic agents (24). Here we show that USP2a mediates suppression of the miRNA cluster miR-34b/c and that the consequent upregulation of MYC is critical for the tumorigenic potential of prostate cancer cells. Importantly, we show that overexpression of USP2a and downregulation of its target $\mathrm{miR}-34 \mathrm{a} / \mathrm{b}$ through the modulation of the MDM2-p53 axis are associated with an invasive phenotype in prostate tumor cells. This is the first example of a mechanistic link between deubiquitination and miRNA expression, which in turn impacts the activity of MYC. These findings suggest that MYC, a driver of as many as one third of human prostate cancers, may be targeted by USP2a or miR-34b/c.

\section{RESULTS}

\section{USP2a Overexpression Downregulates miR-34b/c in Prostate Cells}

To assess alterations in miRNA expression associated with USP2a overexpression, a curated set of prostate-specific miRNAs $(n=51)(10,25,26)$ was quantitated after overexpression of either USP2a ${ }^{\text {WT }}$ or USP2 $\mathrm{a}^{\mathrm{MUT}}$ (C276A and H549R) in immortalized prostate epithelial cells (iPrEC) $(24,27)$ (Fig. 1A). iPrEC-USP2a ${ }^{W T}$ cells exhibit an altered miRNA expression profile relative to the empty vector control and iPrEC-USP $2 \mathrm{a}^{\mathrm{MUT}}$ (Fig. 1B and Supplementary Fig. S1) characterized by significant and WT-specific downregulation of miR-98, the miR-34b/c cluster, and Let-7c and upregulation of miR-18a, miR-19a, and miR-20a. To validate the miRNA signature in cancer cells, the USP $2 \mathrm{a}^{\mathrm{WT}}$-deregulated miRNAs were quantified in the androgen dependent prostate cancer cell line LNCaP. As observed in iPrEC, transfection with exogenous USP2a ${ }^{W T}$ triggers downregulation of $\mathrm{miR}-34 \mathrm{~b} / \mathrm{c}$, miR-98, and let-7c expression levels, whereas miR-18a, 19a, and 20a are significantly induced when compared with USP $2 \mathrm{a}^{\mathrm{MUT}}$ and empty vector controls (Fig. 1C). 
Conversely, siRNA-mediated inhibition of endogenous USP2a expression increases miR-34b/c, miR-98, and let-7c expression by approximately 5-fold (Fig. 1D).

\section{USP2a ${ }^{\text {WT }}$-Deregulated miRNAs Lead to Increased MYC Expression}

In silico predictive models indicate that the whole set of USP2a-downregulated miRNAs potentially target $c$-myc (Supplementary Fig. S2). To verify whether MYC levels are actually affected by USP2a activity, we assayed c-Myc protein levels in control, USP2aWT, and USP $2 \mathrm{a}^{\text {MUT }}$ iPrEC cells. Figure $2 \mathrm{~A}$ shows that overexpression of USP $2 \mathrm{a}^{\mathrm{WT}}$, but not $\mathrm{USP}^{\mathrm{M}} \mathrm{MUT}^{\mathrm{T}}$, enhances MYC protein expression approximately 4-fold compared with parental cells (upper panel) and a corresponding increase in MYC-specific transcription target gene expression (Fig. 2A, bottom panel). However, if MYC is silenced in USP2 $\mathrm{a}^{\mathrm{WT}}$ iPrEC cells (Fig. 2B), its target gene expression (including the MYC-regulated oncogenic miR-17-5p cluster, miR-18a, miR-19a, and miR-20a) (6) is only partially silenced. This is also applicable to other experimental models, because a dose- response induction of USP2 $\mathrm{a}^{\mathrm{WT}}$, but not USP2 $\mathrm{a}^{\mathrm{MUT}}$, in LNCaP cells triggers the progressive upregulation of MYC along with the subset of MYC canonical target genes (Supplementary Fig. S3A). Indeed, MYC silencing in USP2 $\mathrm{a}^{\mathrm{WT}}$-overexpressing transfectants partially reverts the USP2a-induced upregulation of the oncogenic miR-17-5p cluster expression (Supplementary Fig. S3B), similar to what is observed in primary iPrEC cells.

The predicted annealing of miR-34b/c, miR-98, and let-7c to the $3^{\prime}$ UTR of the human $c$ $m y c$ transcript is schematized in Supplementary Figure S4A. Regulation of MYC by the miR-98/Let-7 family has previously been described (15), and both miR-98 and let-7c overexpression are able to reverse USP2a-driven MYC induction (Supplementary Fig. S4B). We then focused on MYC regulation by the miR-34b/c cluster. We first assessed whether MYC upregulation was dependent on miR-34-b/c deregulation in iPrEC cells. Exogenous administration of increasing concentrations of synthetic miR-34b or miR-34c molecules enhances miR-34b and miR-34c levels in a dose-dependent manner (Fig. 2C) while progressively down-regulating MYC protein expression (Fig. 2D). To determine whether this effect was direct, we assayed luciferase (LUC) reporter gene expression in iPrEC cells transfected with a pGL3-promoter vector carrying the c-myc $3^{\prime}$ UTR cloned downstream of the LUC stop codon (28). The relative LUC activity levels were comparable in control and USP $2 \mathrm{a}^{\mathrm{MUT}}$ iPrEC clones but increase by approximately 6 -fold in USP2 $\mathrm{a}^{\mathrm{WT}}$ iPrEC cells (Fig. 2E); moreover, in wild-type cells, the high reporter gene activity is repressed in a dosedependent manner after overexpression of either miR-34b or miR-34c (Fig. 2E). Consistent with the iPrEC data, when USP2 $\mathrm{a}^{\mathrm{WT}}$-expressing $\mathrm{LNCaP}$ cells are transfected with exogenous miR-34b/c, MYC protein expression is impaired (Supplementary Fig. S5A). Similarly, MYC protein is depleted by USP2a silencing (siUSP2a) in LNCaP cells (Supplementary Fig. S5B, top panel) and restored by miR34b/c knockdown in infected cells (Supplementary Fig. S5B, bottom panel).

To verify whether the $c$-myc transcript is a direct target of USP2a-regulated miRNAs, a miR-IP assay was performed. Cells were cotransfected with expression vectors for HAtagged AGO1 and the indicated miRNA mimics molecules (Fig. 2F). The immunoprecipitated RNA was analyzed by quantitative reverse transcription-PCR (qRTPCR) using specfic primers for $c-m y c$ and normalized to 5S rRNA. miR-98 and let7c were included as $c$-myc-targeting positive controls. Relative to input, $c$-myc was significantly ( $P$ $<0.002$ ) enriched in the pulldown with miR-34b and miR-34c, thus demonstrating that $c$ myc mRNA is directly targeted by the miR-34 cluster. To further confirm the inverse relationship between MYC and miRNA expression, we queried the NCBI Gene Expression Omnibus database and identified two data sets in which measurements from the same patients were obtained for both mRNA and miRNA expression [GSE21034 and GSE21036 (29)]. Our analysis confirmed that on progression from a normal prostate to locally invasive 
prostate cancer, decreasing expression levels of hsa-miR-34b and hsa-miR-34c-5p are significantly associated with increasing MYC expression (both by $t$ test and linear regression analyses; Supplementary Fig. S6).

Together these results strongly suggest that the increase in MYC protein caused by USP2a overexpression is mediated by the suppression of miR-34b/c. Thus, the $c$-myc transcript is directly targeted by the miR-34b/c cluster.

\section{USP2a Regulates the miR-34b/c Cluster by Directly Impairing the MDM2-p53 Pathway}

p53-mediated regulation of miR-34b/c and p53 binding sites in the miR-34b/c promoter region have been previously reported $(26,30,31)$. In addition, the miR-34 family including $\mathrm{miR}-34 \mathrm{~b} / \mathrm{c}$ is regulated by $\mathrm{p} 53$ in ovarian tumors (26). However, because miRNAs are both temporal and spatial in their expression, we sought to verify through chromatin immunoprecipitation (ChIP) whether the $\mathrm{p} 53$ protein actually binds to the $\mathrm{p} 53$ putative binding sites (RE1 and RE2 regions) of the miR-34b/c promoter in prostate cancer cells. The human $\mathrm{miR} 34 \mathrm{~b} / \mathrm{c}$ regulatory region was virtually divided into overlapping fragments (regions from A to O; Fig. 3A) and amplified in ChIP assays by specific oligonucleotide pairs in $\mathrm{LNCaP}$ cells. Figure 3B shows that the p53 transcription factor is recruited to the $\mathrm{miR} 34 \mathrm{~b} / \mathrm{c}$ promoter in LNCaP cells, where it exclusively binds to the predicted RE2 region (fragment $\mathrm{F}$ ) in a transcriptionally active status. The specificity of $\mathrm{p} 53$ binding to the $\mathrm{miR}-34 \mathrm{~b} / \mathrm{c}$ promoter was confirmed by ChIP after endogenous p53 silencing (Supplementary Fig. S7A), which was responsible for decreased miR-34b and miR-34c expression and associated with a down-stream increase of MYC protein level (Supplementary Fig. S7B).

USP2a has been previously reported to directly bind and stabilize MDM2 (22). We therefore hypothesized that MDM2 can mediate the USP2a-driven regulation of miR34b/c cluster expression. As expected, we observed that USP2a levels strongly correlated with cellular levels of MDM2 (Supplementary Fig. S8). We next set out to demonstrate that altered MDM2 protein expression is responsible for the USP2a-driven regulation of miR-34b/c cluster expression in LNCaP cells (Fig. 3C). Indeed, ectopic induction of MDM2 reduces the expression of the miR-34b/c cluster. Similarly, MDM2 silencing triggers the overexpression of miR-34b/c (Fig. 3C). These results are supported by ChIP results that clearly demonstrate reduced p53 binding to the RE2 sequence (as seen with USP2a ${ }^{\text {WT }}$ overexpression) in cells overexpressing MDM2 (Fig. 3D). Conversely, small intefering RNA-mediated silencing of MDM2 in the USP2 $\mathrm{a}^{\text {WT }}$ clone activates $\mathrm{p} 53$ and enhances its downstream recruitment to both the RE1 and RE2 containing sequences (Fig. 3D). Furthermore, treatment with Nutlin-3a (a specific MDM2 inhibitor) leads to dose-dependent activation of $\mathrm{p} 53$ in $\mathrm{LNCaP}$ cells with resultant upregulation of miR-34b/c and downregulation of MYC (Fig. 3E). Different p53 putative binding boxes have also been identified along the $5^{\prime}$ upstream regions (up to $50 \mathrm{~kb}$ ) of both the miR-98 and let-7c genomic loci (Supplementary Fig. S9A). Both miRs are modulated by USP2a ${ }^{\text {WT }}$ and are directly involved in the USP2a-mediated modulation of MYC expression; however, miR-98 and let-7c are not regulated by p53 in prostate cancer cells. In fact, direct and USP2amediated p53 inhibition (Supplementary Fig. S9B) together with siUSP2a and Nutlinmediated p53 induction (Supplementary Fig. S9C) are both unable to affect miR-98/let-7c expression or trigger 533 recruitment to its response elements in miR regulatory regions in LNCaP cells (Supplementary Fig. S9D). Our data suggest that, in prostate cancer cells, USP2a-mediated induction of MDM2 and subsequent degradation of p53 impedes the transcription of the miR-34b/c miRNA cluster.

To verify the biochemical effect of USP2a expression on the MDM2-p53 pathway and the subsequent impact on MYC protein expression, we carried out a time-course experiment to 
measure the levels of USP2a, MDM2, p53, and MYC and miR-34b/c at different points after USP2a ${ }^{\text {WT }}$ overexpression in LNCaP cells (Fig. 4). USP2a expression is first detectable at 12 hours posttransfection and is sustained during the first 36 hours. Subsequently, MDM2 is upregulated (24-36 hours posttransfection) and p53 is downregulated (36-60 hours posttransfection). Although the decrease in miR-34b/c expression occurs as early as 12 hours after USP2a transfection, the final effect on MYC overexpression is evident after 60 to 72 hours. We confirmed these results by using a prostate cell line (PC3) devoid of p53.

When we restore wild-type p53 presence under USP2a expression, we observe a decrease in MYC expression similar to LNCaP. Conversely, nondegradable p53 mutants $(\Delta 13-19$ or $22 \mathrm{Gln} / 23 \mathrm{Ser}$ ) and USP2a coexpression lead to an upregulation of MYC expression (data not shown). Taken together, these results suggest that USP2a regulates MYC expression through the MDM2-p53 axis.

\section{mRNA Signature of USP2a-Overexpressing Cells}

To characterize the molecular signature associated with USP2a overexpression, we next analyzed differential gene expression in iPrEC transfected with USP2 $\mathrm{a}^{\mathrm{WT}}$ and USP $2 \mathrm{a}^{\mathrm{MUT}}$ using the Affymetrix Human Genome U133 Plus 2.0 Array (Fig. 5). Empty vector was used as a control (EV). Direct comparison of the three distinct groups of samples (WT, MUT, EV) revealed robust differential expression of distinct sets of genes and cellular pathways associated with the expression of USP2 $\mathrm{a}^{\mathrm{WT}}$. A total of 789 genes were differentially expressed between USP2 $\mathrm{a}^{\text {WT }}$ and USP2a ${ }^{\text {MUT }} ; 848$ genes were differentially expressed between USP2 $\mathrm{a}^{\text {WT }}$ and EV; 54 genes were differentially expressed between USP2a ${ }^{\text {MUT }}$ and $\mathrm{EV}(P<0.0001$ after adjustment for multiple testing in all pairwise comparisons). USP2a overexpression was associated with a global gene expression upregulation, and mRNA transcripts for several cancer-related genes such as $c$-myc were more highly expressed in the USP2 $\mathrm{a}^{\mathrm{WT}}$ group compared with either the USP $2 \mathrm{a}^{\mathrm{MUT}}$ or EV cell lines. Complete lists of differentially expressed genes for the pairwise comparisons can be accessed online (32). We further show that the gene expression signatures USP $2 \mathrm{a}^{\mathrm{MUT}}$ and EV cell lines are indistinguishable and differ markedly from the discrete gene expression signature associated with USP2a ${ }^{\mathrm{WT}}$ at both the gene and pathway levels [Fig. 5A; see also volcano and "correspondence-at-the-top" (CAT) plots shown in Supplementary Fig. S10 and Supplementary Fig. S11]. We next applied the one-sided Wilcoxon rank-sum test to investigate differential enrichment of 86170 functional gene sets corresponding to specific annotation and biological themes in iPrEC transfected with either USP $2 \mathrm{a}^{\mathrm{WT}}$ or USP $2 \mathrm{a}^{\mathrm{MUT}}$ relative to EV control. Functional gene sets were retrieved from a variety of genomics databases, enabling the interrogation of cellular pathways, protein networks, transcription factors, miRNA targets, genomic locations, enzymatic activities, and cellular processes. This analysis indicated that MYC-related functional gene lists were associated with USP2 ${ }^{\text {WT }}$ overexpression (in contrast to USP2 $\mathrm{a}^{\mathrm{MUT}}$ and $\mathrm{EV}$ ). Global upregulation of genes transcribed by MYC (33) and of miR-34c mRNA targets (34) was mirrored by the overall downregulation of genes repressed by p21 in a p53-dependent manner (35) and targeted by miR-19a [34 (Fig. 5B)]. The complete thematic list and functional pathways differentially enriched between USP2aWT and USP2 $\mathrm{a}^{\mathrm{MUT}}$ cell lines can be accessed online (32). Finally, we compared both USP2a $\mathrm{a}^{\mathrm{WT}}$ - and USP $2 \mathrm{a}^{\mathrm{MUT}}$-specific gene expression signatures (i.e., the nonoverlapping segments of the Venn diagrams in Fig. 5A) to a large, publically available laser capture microdissected prostate cancer data set [GSE69099 data set (36); Fig. 5C]. We similarly used gene set analysis also to evaluate whether up- and downregulated USP2a gene lists were consistently enriched along prostate cancer progression. Genes upregulated on transfection of USP $2 \mathrm{a}^{\mathrm{WT}}$ are enriched in the epithelial compartment of human prostate cancer, whereas genes upregulated by USP $2 \mathrm{a}^{\mathrm{MUT}}$ are enriched in the stromal compartment. Interestingly, USP2 $\mathrm{a}^{\mathrm{WT}}$ genes appeared to be strongly upregulated during local invasion of 
cancer cells, because they were most strongly enriched when locally invasive cancers were compared with prostatic intraepithelial neoplasia specimens (Fig. 5C).

\section{Targeting MYC in USP2a-Overexpressing Cells Suppresses Growth and Invasion}

USP2a modulation of MYC protein expression may have important biologic implications for the natural history of prostate cancer. We demonstrate that the proliferative capacity, cell viability, and clonogenic ability of LNCaP USP $2 \mathrm{a}^{\mathrm{WT}}$ cells can be significantly impaired by targeting MYC expression. This can be achieved by direct silencing of MYC, by administration of Nutlin-3a, or by treating USP2 $\mathrm{a}^{\mathrm{WT}}$ cells with synthetic miR-34b/c molecules (Supplementary Fig. S12).

Because enrichment of the genes upregulated by USP2A $\mathrm{A}^{\mathrm{WT}}$ is observed during local invasion of prostate cancer (Fig. 5C), we next analyzed publicly available gene expression profiles of a number of distinct cancer invasion models. CAT-plot analysis revealed significant agreement between genes upregulated by USP $2 \mathrm{a}^{\mathrm{WT}}$ and those upregulated on invasion in each model considered $(P<0.001)$. The strongest agreement was observed with migration efficiency/velocity in Boyden chamber assays using cell lines from prostate and other cancers (Fig. 6). Interestingly, in the prostasphere invasion model, the strongest agreement was observed between the USP2a signature and the genes differentially expressed between the "stellate" and "mass" phenotypes, whereas overlap was observed when the comparison involved the "round/branching" noninvasive phenotypes (data not shown). The "stellate" phenotype corresponds to invading cancer cell lines, the "mass" phenotype to noninvasive cancer cell lines and transformed normal prostatic epithelial cells, and the "round/branching" phenotype to iPrECs and non-transformed lines. In agreement with the CAT-plot analysis, the in vitro invasion test demonstrates that UPS2a ${ }^{\mathrm{WT}}$ overexpression increases the invasive ability of iPrEC when compared with control or USP2aMUT transfected cells, and, when silenced in an LNCaP experimental model, reduces invasion by almost 2-fold (Fig. 6C). miR-34b/c seems to be involved in the USP2a-mediated invasiveness, because modulation of their expression by either mimic treatment in $\mathrm{PrEC}-$ USP $2 \mathrm{a}^{\text {WT }}$ cells or by antago-miR addition to USP2a-silenced LNCaP cells is able to significantly affect the relative prostate invasive ability (Fig. 6C).

\section{DISCUSSION}

Deubiquitinating enzymes can prevent destruction of protein substrates before proteosomal degradation. USP2a deubiquitinates the antiapoptotic proteins fatty acid synthase, the ubiquitin ligase MDM2, and cyclin D1. USP2a is overexpressed in approximately $40 \%$ of human prostate adenocarcinomas (24) and exhibits oncogenic behavior both in vitro and in vivo. In addition, USP2a silencing in several human cancer cell lines results in apoptosis.

Oncogenic activation of $c$-myc is one of the most frequent events in human malignancy in general and prostate cancer in particular. $c$-myc is a master regulatory gene that can globally reprogram cells to proliferate or undergo apoptosis through induction or repression of transcription. There are a number of molecular mechanisms hypothesized for the oncogenic function of MYC (1, 37-40). Importantly, this study highlights a previously unrecognized mechanism of MYC regulation establishing a novel link between deubiquitination, miRNA deregulation, and the p53/MYC regulatory network. Gene set enrichment analysis of microarray expression in human tumors highlights a MYC-related gene set supporting the link between USP2a and MYC. Indeed, the MYC-related gene set associated with USP2a $\mathrm{WT}^{\mathrm{WT}}$ overexpression is differentially expressed between cancer and the normal prostate and, importantly, these genes are associated with prostate tumor progression. Specifically, we show that the proliferative capacity, cell viability, clonogenic ability, and invasive properties of USP2a ${ }^{\text {WT }}$ overexpressing cells can be significantly impaired by targeting MYC 
expression. Although novel therapeutics to target MYC-dependent tumors have been developed (41-43), these are generally not effective. This study provides evidence that, at least in prostate cancer, MYC may be affected by targeting either USP2a or MDM2.

Although studies addressing the role of miRNAs in cancer pathogenesis are at an early stage, it is clear that miRNA expression patterns correlate strikingly with disease progression and response to therapy (44). However, the biological roles of only a very limited number of miRNAs have been elucidated in cancer cells. The downregulation of $\mathrm{miR}-34 \mathrm{~b} / \mathrm{c}$ expression that results from USP2a overexpression suggests a direct role of the $\mathrm{miR}-34 \mathrm{~b} / \mathrm{c}$ cluster as a potential tumor suppressor in prostate cancer. Furthermore, the regulation of miRNAs by USP2 $\mathrm{a}^{\mathrm{WT}}$ is the first example of the ubiquitin-proteasome pathway playing a role in miRNA biology. We outline our proposed model for this mechanism in Figure 7.

Several studies have demonstrated the use of developing specific inhibitors of ubiquitin ligases and deubiquitinating enzymes as valuable therapeutic strategies against cancer (45, 46). Our results further underscore the importance of these therapeutic strategies and suggest that USP2a inhibitors may offer a potentially viable means of targeting MYC-dependent prostate cancer.

\section{METHODS}

\section{Cell Culture}

Empty vector (Vector), wild-type (USP2a $\mathrm{a}^{\mathrm{WT}}$ ), and mutant (USP2 $\mathrm{a}^{\mathrm{MUT}}$ ) stable clones (previously established by infecting iPrEC $[23,24]$ were grown in specific PrEBM medium; Cambrex) and selected in $1.6 \mu \mathrm{g} / \mathrm{mL}$ puromycin. Human prostate adenocarcinoma LNCaP and PC 3 cells were obtained from the American Type Culture Collection (ATCC) and grown in RPMI-1640 medium (Invitrogen, Life Technologies) containing 10\% fetal bovine serum (GIBCO-Invitrogen) and 1\% penicillin-streptomycin (Invitrogen). Cell lines were purchased from ATCC in 2006. Both LNCaP and PC3 cells have been periodically tested (every 3 months) for cell morphology, growth rate, colony-forming ability, and gene expression of both p53 and AR. Moreover, cells have undergone a contamination test for excluding mycoplasma presence by Hoechst staining and PCR-based exogenous DNA detection.

\section{Cell Transfection and Luciferase Reporter Assay}

Transient transfection experiments were carried out by seeding cells in $60-\mathrm{mm}$ Petri dishes in complete medium $\left(2 \times 10^{5}\right.$ cells/plate). Transfection was performed 24 hours after plating using Lipofectamine 2000 reagent in Optimem medium (Invitrogen) for siRNA oligonucleotides (100-500 nM) and synthetic/knockdown miR molecules (10-50 nM) and by JetPei reagent (PloyPlus-Transfection) in complete medium for expression vectors $(0.5-5$ $\mu \mathrm{g}$ ) and LUC-reporter plasmids. Evaluation of protein, mRNA, and miRNA expression levels was performed by harvesting cells at 24-hour intervals (24-120 hours) after transfection. For LUC reporter assays, cells were cotransfected with the pGL3-myc UTR vector $(1 \mu \mathrm{g}$ ) and PEQ-176 (expressing the control $\beta$-galactosidase enzyme, $1 \mu \mathrm{g}$ ); scrambled (CTR), or increasing concentrations of synthetic miR sequences were added to the transfection mix for iPrEC-USP2aWT cells. Forty-eight to 96 hours later, cells were rinsed with cold phosphate-buffered saline, resuspended in cell lysis buffer (Promega), and incubated for 10 minutes at room temperature. Insoluble material was spun down, and LUC activity was quantified by a commercially available kit (Promega) on a TD-20E luminometer (Turner Biosystems). Luciferase values were normalized to protein contents 
and $\beta$-galactosidase expression. All sequences of siRNA are reported in Supplementary Table S1.

\section{Western Blot}

Cell lysis was performed on ice for 30 minutes in RIPA buffer $(50 \mathrm{mM}$ Tris- $\mathrm{HCl} \mathrm{pH}$ 7.4, $150 \mathrm{mM} \mathrm{NaCl}, 1 \% \mathrm{NP}-40,0.25 \%$ sodium deoxycholate, $1 \mathrm{mM}$ EDTA) supplemented with phosphatase inhibitors ( $1 \mathrm{mM}$ PMSF, $1 \mu \mathrm{g} / \mathrm{mL}$ aprotinin, leupeptin, pepstatin). Equal amounts of total protein extracts $(20-80 \mu \mathrm{g})$ were resolved by $10 \%, 12 \%$, or $15 \%$ denaturing sodium dodecyl sulphate-polyacrylamide gel electrophoresis and transferred for 4 hours to polyvinylidene difluoride membrane. Membranes were blocked in 5\% milk-phosphatebuffered saline- $0.05 \%$ Tween 20 for 1 hour and incubated overnight with the specific primary antibodies. Secondary antibodies were horseradish peroxidase-conjugated (Santa Cruz), and ECL reagent (Amersham, GE Healthcare) was used for chemoluminescence detection.

\section{RNA Isolation and qRT-PCR for mRNA Analysis}

Total RNA was extracted using Trizol Reagent (Invitrogen). RNA quantity and integrity were assessed using a NanoDrop Spectrophotometer (Thermo Scientific) and an Agilent 2100 Bioanalyzer (Agilent Technologies), respectively. For cDNA synthesis, $2 \mu \mathrm{g}$ of total RNA was reverse-transcribed with random primers by a Moloney murine leukemia virus reverse transcriptase kit (M-MLV RT kit; Invitrogen), according to the manufacturer's instructions. Semiquantitative RT-PCR was performed with the Applied Biosystems Taq enzyme (Applied Biosystems by Life Technologies) using $2 \mu \mathrm{L}$ of cDNA. Polymerase chain reaction conditions were as follows: one cycle at $94^{\circ} \mathrm{C}(5$ minutes $) ; 23-35$ cycles at $94^{\circ} \mathrm{C}$ (30 seconds), $58^{\circ} \mathrm{C}$ ( 40 seconds), $72^{\circ} \mathrm{C}$ (40 seconds); and one cycle at $72^{\circ} \mathrm{C}$ ( 7 minutes). Polymerase chain reaction products were run on a $2 \%$ agarose gel and visualized with ethidium bromide. Gene transcript expression was normalized to glyceraldehyde-3phosphate dehydrogenase levels. qRT-PCR was carried out with $1 \mu \mathrm{L}$ of cDNA using SYBR Green master mix (Applied Biosystems) and analyzed on a StepOne Plus Real Time PCR Detection System (Applied Biosystems). All reactions were run in triplicate and the relative abundance of specific mRNA levels was calculated by normalizing to both glyceraldehyde-3-phosphate dehydrogenase and aldolase A expression using the $2^{-\Delta \Delta \mathrm{Ct}}$ method (47). All sequences of oligonucleotide primers are reported in Supplementary Tables S2-3.

\section{Immunoprecipitation of miRNA Targets}

PC 3 cells $\left(0.5 \times 10^{6}\right.$ cells) were cotransfected with $1 \mu \mathrm{g}$ of HAAGO1 (pIRES-FLAG/HA vector; Addgene) and $50 \mathrm{nM}$ of miRNA mimics using Lipofectamine 2000 (Invitrogen). After 2 days, cells were harvested using $400 \mu \mathrm{L}$ lysis buffer $(100 \mathrm{mM} \mathrm{KCl}, 5 \mathrm{mM} \mathrm{MgCl} 2$, $10 \mathrm{mM}$ HEPES, $\mathrm{pH}$ 7.0, 0.5\% Nonidet P-40) containing freshly added RNaseOUT (Invitrogen) and Protease Inhibitor Cocktail (Roche). After centrifugation, a 50- $\mu \mathrm{L}$ aliquot of supernatant was taken as input for subsequent RNA extraction. The remaining supernatant was gently shaken with HA-beads (HA-probe Santa Cruz sc-7392) for 4 hours at $40^{\circ} \mathrm{C}$ in Spin Columns-Screw Cap (Pierce). The columns were drained, washed, and the retained beads were treated with $5 \mathrm{U}$ DNaseI in NT2 buffer $(50 \mathrm{mM}$ Tris, $\mathrm{pH} 7.4,150 \mathrm{mM}$ $\mathrm{NaCl}, 1 \mathrm{mM} \mathrm{MgCl} 2,0.05 \%$ Nonidet P-40) for 10 minutes at $37^{\circ} \mathrm{C}$, washed with NT2, and then treated with Proteinase K in NT2 plus 1\% sodium dodecyl sulphate for 30 minutes at $55^{\circ} \mathrm{C}$. Finally the beads were resuspended in NT2 buffer and RNA was extracted using acid phenolcholoroform (Ambion-Applied Biosystems) to extract RNA. RNA was reversetranscribed and analyzed with quantitative PCR for enrichment of $c$-myc mRNA. 


\section{Chromatin Immunoprecipitation Assay}

Cells were washed with phosphate-buffered saline (supplemented with phosphatase inhibitors) and incubated for 10 minutes with $1 \%$ formaldehyde at room temperature. Formaldehyde crosslinking was stopped by adding glycine, $\mathrm{pH} 2.5$ (125 mM final concentration), for 5 minutes at room temperature. Cells were scraped off the plates, lysated in sodium dodecyl sulphate lysis buffer (1\% sodium dodecyl sulphate, 10 mM EDTA, 50 $\mathrm{mM}$ Tris- $\mathrm{HCl}, \mathrm{pH} 8$, plus protease inhibitor mixture), and sonicated to generate 500- to 2000-bp fragments. After centrifugation, the supernatant was diluted 10-fold in immunoprecipitation buffer (50 mM Tris- $\mathrm{HCl}, \mathrm{pH} 8,150 \mathrm{mM} \mathrm{NaCl}, 5 \mathrm{MM}$ EDTA, $0.5 \%$ Nonidet P-40) and incubated at $4^{\circ} \mathrm{C}$ with Protein A/G beads (Pierce) (previously adsorbed with sonicated single-stranded DNA and bovine serum albumin). The cleared lysate was incubated overnight with specific antibody, and the immune complex was further precipitated with protein A/G. After centrifugation, the beads were washed and the antigen eluted with $1 \%$ sodium dodecyl sulphate and $100 \mathrm{mM}$ sodium carbonate. DNA-protein crosslinks were reversed by heating at $65^{\circ} \mathrm{C}$ for $4-5$ hours, and DNA was phenol-extracted and ethanol-precipitated. Amplification of specific regions on genomic immunoprecipitated chromatin was carried out by PCR with the Applied Biosystem Taq enzyme (Applied Biosystems) using $2 \mu \mathrm{L}$ of DNA. Polymerase chain reaction conditions were as follows: one cycle at $94^{\circ} \mathrm{C}$ (5 minutes); 28 to 35 cycles at $94^{\circ} \mathrm{C}$ ( 30 seconds), $58^{\circ} \mathrm{C}$ ( 40 seconds), $72^{\circ} \mathrm{C}$ (40 seconds); and one cycle at $72^{\circ} \mathrm{C}$ (5 minutes). PCR products were run on a $2 \%$ agarose gel and visualized with ethidium bromide. Details of the in silico analysis of putative miRNA promoters and oligonucleotide primer sequences for the ChIP assay are outlined in Supplementary Information and Supplementary Tables S4-7.

\section{qRT-PCR for miRNA Analysis}

Analysis of miRNA expression was carried out on total RNA using real-time stem-loop reverse transcription-PCR according to the manufacturer's protocol (Taqman miRNA assays are available as assays on demand; Applied Biosystems). Briefly, $10 \mathrm{ng}$ of total RNA was reverse-transcribed with specific miR stem-loop primer and subsequently amplified by miR-specific primers. qRT-PCR was done using a StepOne Plus Real Time PCR Detection System (Applied Biosystems). All reactions were run in triplicate and the relative abundance of specific miRs was calculated by normalizing to small nucleolar RNAs using the $2^{-\Delta \Delta C t}$ method (47).

\section{In Vitro Cell Invasion Analysis}

Cell invasion ability was assessed using the Chemicon Invasion Chamber (Chemicon, Millipore), a tissue culture plate modified with insert containing an 8 - $\mu \mathrm{m}$ pore size polycarbonate membrane over which a thin layer of ECMatrix is dried. Briefly, inserts were hydrated for 2 hours with $300 \mu \mathrm{L}$ of warm serum-free media at $37^{\circ} \mathrm{C}$ with $5 \% \mathrm{CO}_{2}$. After carefully removing medium from the inserts, $500 \mu \mathrm{L}$ of medium (PrEBM plus supplements and RPMI with $10 \%$ fetal bovine serum for iPrEC and LNCaP cells, respectively) were added to the lower chamber, whereas $300 \mu \mathrm{L}$ of cell suspension $\left(10^{6}\right.$ cells $\left./ \mathrm{mL}\right)$ of $\mathrm{iPrEC}$ clones in PrEBM and LNCaP cells in RPMI plus $2 \%$ fetal bovine serum (siControl or siUSP2a-treated before harvest) were added to the top chambers. Cells were allowed to invade for 48 hours (iPrEC) or 24 hours $(\mathrm{LNCaP})$ at $37^{\circ} \mathrm{C}$ with $5 \% \mathrm{CO}_{2}$. After incusbation, noninvading cells were gently removed from the interior of the inserts with a cotton-tipped swab. Invasive cells on the lower surface of the membrane were stained by dipping inserts in the kit staining solution for 20 minutes and washing several times in water. After air-drying, stained cells were dissolved in 10\% acetic acid (100-200 $\mu \mathrm{L} /$ well) and quantitated by reading $\mathrm{OD}$ at $560 \mathrm{~nm}$. 


\section{Statistical Analysis}

All data are presented as mean \pm standard deviation calculated for 3 or more replicates. All statistical analyses were performed using an unpaired 2-tailed $t$ test using SPSS Software Version 1 , unless differently specified. $P$ values $<0.05$ were taken as statistically significant.

\section{Gene Expression Profiling and Functional Annotation Analysis}

Total RNA was extracted from iPrEC cells using Trizol (Invitrogen) purified using a DNase I (Qiagen) digestion step and further enriched using Qiagen RNeasy columns. RNA quantity and integrity were assessed using a NanoDrop Spectrophotometer (Thermo Scientific) and an Agilent 2100 Bioanalyzer (Agilent Technologies), respectively. Five replicates of EV, USP2 $\mathrm{a}^{\mathrm{WT}}$, and USP2a ${ }^{\mathrm{MUT}}$, respectively, were run on the Human Genome U133 Plus 2.0 Array from Affymetrix as previously described (48). A detailed description of the methods used for array data annotation, processing and analysis, and public data sets used in the present study are described in the Supplementary Methods section.

\section{Analysis of mRNA Signature of Distinct Cancer Invasion Models}

For migration efficiency/velocity in Boyden assays, on a review of the literature (see supplementary references) we identified a number of cell lines from various cancer types displaying extreme differences in migration efficiency/velocity as assayed in Boyden assays, as reported in Supplementary Tables S8-10, and retrieved the corresponding Affymetrix raw gene expression data from the NCBI GEO database. Using the same generalized linear model approach applied to analyze gene expression on USP2a transfection, we analyzed differential gene expression between fast- and slow-migrating prostate cancer cell lines (PC3 and LNCaP, respectively) (Supplementary Table S9). Similarly, to avoid confounding with experimental batch and cell lines characteristics (i.e., androgen sensitivity), we also analyzed migration efficiency/velocity in Boyden assays in a balanced compounded data set accounting for several cancer cell lines of different tissue origin) (Supplementary Table S10). For three-dimensional model of prostate cancer invasion, we also analyzed differential gene expression associated with prostaspheres displaying distinct patterns of invasion in Matrigel. To this end we retrieved and analyzed gene expression data from the GSE19426 series (1) comparing prostaspheres with distinct growth and invasion behavior ("round," "branching," "mass," and "stellate," as described by Harma and colleagues [see supplementary references]) using a generalized linear model approach as applied to analyze gene expression on USP2a transfection. A description of the phenotypic groups compared is available in Supplementary Table S11. For prostate gland branching morphogenesis, the gene expression signature of prostate gland branching morphogenesis was obtained by comparing mouse male and female urogenital sinuses at gestational day $17( \pm 0.5)$ as analyzed in Schaeffer and colleagues (see supplementary references) (GSE12077).

\section{Supplementary Material}

Refer to Web version on PubMed Central for supplementary material.

\section{Acknowledgments}

We thank Carmen Priolo for providing iPrEC USP2a WT and USP2 ${ }_{a}$ MUT cells, Prof. Moshe Oren (Weizmann Institute of Science, Rehovot, Israel) for kindly providing the pCDNA3-MDM2 (pMDM2) expression vector, and Dr. Yatrik Shah (National Cancer Institute) for sending us the pGL3-LUC-c-myc-3'-UTR. We also thank Stefano Sioletic for helpful contribution to the assessment of USP2a-myc relationship in human specimens.

Grant Support 
This work was supported by National Cancer Institute grants RO1CA131945, PO1CA89021, and P50CA90381 to M. Loda and a gift from Nuclea Biomarkers to the laboratory of M. Loda; NIH grant P30CA006973 to L. Marchionni; and European Community (EC) Active p53 Program to G. Blandino. Sabbatical research fellowship (CAPES \#3665/10-0) and salary support are provided by Brazilian Government to S. Zanata.

\section{REFERENCES}

1. Nesbit CE, Tersak JM, Prochownik EV. MYC oncogenes and human neoplastic disease. Oncogene. 1999; 18:3004-3016. [PubMed: 10378696]

2. Sato K, Qian J, Slezak JM, Lieber MM, Bostwick DG, Bergstralh EJ, et al. Clinical significance of alterations of chromosome 8 in high-grade, advanced, nonmetastatic prostate carcinoma. J Natl Cancer Inst. 1999; 91:1574-1580. [PubMed: 10491435]

3. Ellwood-Yen K, Graeber TG, Wongvipat J, Iruela-Arispe ML, Zhang J, Matusik R, et al. Mycdriven murine prostate cancer shares molecular features with human prostate tumors. Cancer Cell. 2003; 4:223-238. [PubMed: 14522256]

4. Chang TC, Yu D, Lee YS, Wentzel EA, Arking DE, West KM, et al. Widespread microRNA repression by Myc contributes to tumorigenesis. Nat Genet. 2008; 40:43-50. [PubMed: 18066065]

5. Dai MS, Jin Y, Gallegos JR, Lu H. Balance of Yin and Yang: ubiquitylation-mediated regulation of p53 and c-Myc. Neoplasia. 2006; 8:630-644. [PubMed: 16925946]

6. He L, Thomson JM, Hemann MT, Hernando-Monge E, Mu D, Goodson S, et al. A microRNA polycistron as a potential human oncogene. Nature. 2005; 435:828-833. [PubMed: 15944707]

7. Popov N, Wanzel M, Madiredjo M, Zhang D, Beijersbergen R, Bernards R, et al. The ubiquitinspecific protease USP28 is required for MYC stability. Nat Cell Biol. 2007; 9:765-774. [PubMed: 17558397]

8. Wei JS, Song YK, Durinck S, Chen QR, Cheuk AT, Tsang P, et al. The MYCN oncogene is a direct target of miR-34a. Oncogene. 2008; 27:5204-5213. [PubMed: 18504438]

9. Ambs S, Prueitt RL, Yi M, Hudson RS, Howe TM, Petrocca F, et al. Genomic profiling of microRNA and messenger RNA reveals deregulated microRNA expression in prostate cancer. Cancer Res. 2008; 68:6162-6170. [PubMed: 18676839]

10. Volinia S, Calin GA, Liu CG, Ambs S, Cimmino A, Petrocca F, et al. A microRNA expression signature of human solid tumors defines cancer gene targets. Proc Natl Acad Sci U S A. 2006; 103:2257-2261. [PubMed: 16461460]

11. Kumar MS, Lu J, Mercer KL, Golub TR, Jacks T. Impaired microRNA processing enhances cellular transformation and tumorigenesis. Nat Genet. 2007; 39:673-677. [PubMed: 17401365]

12. Koscianska E, Baev V, Skreka K, Oikonomaki K, Rusinov V, Tabler M, et al. Prediction and preliminary validation of oncogene regulation by miRNAs. BMC Mol Biol. 2007; 8:79. [PubMed: 17877811]

13. Leucci E, Cocco M, Onnis A, De Falco G, van Cleef P, Bellan C, et al. MYC translocationnegative classical Burkitt lymphoma cases: an alternative pathogenetic mechanism involving miRNA deregulation. J Pathol. 2008; 216:440-450. [PubMed: 18802929]

14. Sachdeva M, Zhu S, Wu F, Wu H, Walia V, Kumar S, et al. p53 represses c-Myc through induction of the tumor suppressor miR-145. Proc Natl Acad Sci U S A. 2009; 106:3207-3212. [PubMed: 19202062]

15. Sampson VB, Rong NH, Han J, Yang Q, Aris V, Soteropoulos P, et al. MicroRNA let-7a downregulates MYC and reverts MYC-induced growth in Burkitt lymphoma cells. Cancer Res. 2007; 67:9762-9770. [PubMed: 17942906]

16. O’Donnell KA, Wentzel EA, Zeller KI, Dang CV, Mendell JT. c-Myc-regulated microRNAs modulate E2F1 expression. Nature. 2005; 435:839-843. [PubMed: 15944709]

17. Nijman SM, Luna-Vargas MP, Velds A, Brummelkamp TR, Dirac AM, Sixma TK, et al. A genomic and functional inventory of deubiquitinating enzymes. Cell. 2005; 123:773-786. [PubMed: 16325574]

18. Cummins JM, Vogelstein B. HAUSP is required for p53 destabilization. Cell Cycle. 2004; 3:689692. [PubMed: 15118411]

19. Li M, Chen D, Shiloh A, Luo J, Nikolaev AY, Qin J, et al. Deubiquitination of p53 by HAUSP is an important pathway for p53 stabilization. Nature. 2002; 416:648-653. [PubMed: 11923872] 
20. Meulmeester E, Maurice MM, Boutell C, Teunisse AF, Ovaa H, Abraham TE, et al. Loss of HAUSP-mediated deubiquitination contributes to DNA damage-induced destabilization of Hdmx and Hdm2. Mol Cell. 2005; 18:565-576. [PubMed: 15916963]

21. Shan J, Zhao W, Gu W. Suppression of cancer cell growth by promoting cyclin D1 degradation. Mol Cell. 2009; 36:469-476. [PubMed: 19917254]

22. Stevenson LF, Sparks A, Allende-Vega N, Xirodimas DP, Lane DP, Saville MK. The deubiquitinating enzyme USP2a regulates the p53 pathway by targeting Mdm2. Embo J. 2007; 26:976-986. [PubMed: 17290220]

23. Graner E, Tang D, Rossi S, Baron A, Migita T, Weinstein LJ, et al. The isopeptidase USP2a regulates the stability of fatty acid synthase in prostate cancer. Cancer Cell. 2004; 5:253-261. [PubMed: 15050917]

24. Priolo C, Tang D, Brahamandan M, Benassi B, Sicinska E, Ogino S, et al. The isopeptidase USP2a protects human prostate cancer from apoptosis. Cancer Res. 2006; 66:8625-8632. [PubMed: 16951176]

25. Shi XB, Xue L, Yang J, Ma AH, Zhao J, Xu M, et al. An androgen-regulated miRNA suppresses Bak1 expression and induces androgen-independent growth of prostate cancer cells. Proc Natl Acad Sci U S A. 2007; 104:19983-19988. [PubMed: 18056640]

26. Tong AW, Fulgham P, Jay C, Chen P, Khalil I, Liu S, et al. MicroRNA profile analysis of human prostate cancers. Cancer Gene Ther. 2009; 16:206-216. [PubMed: 18949015]

27. Berger R, Febbo PG, Majumder PK, Zhao JJ, Mukherjee S, Signoretti S, et al. Androgen-induced differentiation and tumorigenicity of human prostate epithelial cells. 2004; 64:8867.

28. Shah YM, Morimura K, Yang Q, Tanabe T, Takagi M, Gonzalez FJ. Peroxisome proliferatoractivated receptor alpha regulates a microRNA- mediated signaling cascade responsible for hepatocellular proliferation. Mol Cell Biol. 2007; 27:4238-4247. [PubMed: 17438130]

29. Taylor BS, Schultz N, Hieronymus H, Gopalan A, Xiao Y, Carver BS, et al. Integrative genomic profiling of human prostate cancer. Cancer Cell. 2010; 18:11-22. [PubMed: 20579941]

30. Corney DC, Flesken-Nikiti A, Godwin AK, Wang W, Nikitin AY. MicroRNA-34b and MicroRNA-34c are targets of p53 and cooperate in control of cell proliferation and adhesionindependent growth. Cancer Res. 2007; 67:8433-8438. [PubMed: 17823410]

31. Hermeking H. p53 enters the microRNA world. Cancer Cell. 2007; 12:414-418. [PubMed: 17996645]

32. Available at: http://astor.som.jhmi.edu/ marchion/labML/benassi.html.

33. Bild AH, Yao G, Chang JT, Wang Q, Potti A, Chasse D, et al. Oncogenic pathway signatures in human cancers as a guide to targeted therapies. Nature. 2006; 439:353-357. [PubMed: 16273092]

34. Megraw M, Sethupathy P, Corda B, Hatzigeorgiou AG. miRGen: a database for the study of animal microRNA genomic organization and function. Nucleic Acids Res. 2007; 35:D149-D155. [PubMed: 17108354]

35. Wu Q, Kirschmeier P, Hockenberry T, Yang TY, Brassard DL, Wang L, et al. Transcriptional regulation during $\mathrm{p} 21 \mathrm{WAF} 1 / \mathrm{CIP} 1$-induced apoptosis in human ovarian cancer cells. J Biol Chem. 2002; 277:36329-36337. [PubMed: 12138103]

36. Tomlins SA, Mehra R, Rhodes DR, Cao X, Wang L, Dhanasekaran SM, et al. Integrative molecular concept modeling of prostate cancer progression. Nat Genet. 2007; 39:41-51. [PubMed: 17173048]

37. Amati B, Dalton S, Brooks MW, Littlewood TD, Evan GI, Land H. Transcriptional activation by the human c-Myc oncoprotein in yeast requires interaction with Max. Nature. 1992; 359:423-426. [PubMed: 1406955]

38. Gurel B, Iwata T, Koh CM, Jenkins RB, Lan F, Van Dang C, et al. Nuclear MYC protein overexpression is an early alteration in human prostate carcinogenesis. Mod Pathol. 2008; 21:1156-1167. [PubMed: 18567993]

39. Adhikary S, Eilers M. Transcriptional regulation and transformation by Myc proteins. Nat Rev Mol Cell Biol. 2005; 6:635-645. [PubMed: 16064138]

40. Ayer DE, Kretzner L, Eisenman RN. Mad: a heterodimeric partner for Max that antagonizes Myc transcriptional activity. Cell. 1993; 72:211-222. [PubMed: 8425218] 
41. Bressin C, Bourgarel-Rey V, Carre M, Pourroy B, Arango D, Braguer D, et al. Decrease in c-Myc activity enhances cancer cell sensitivity to vinblastine. Anticancer Drugs. 2006; 17:181-187. [PubMed: 16428936]

42. el-Deiry WS. Role of oncogenes in resistance and killing by cancer therapeutic agents. Curr Opin Oncol. 1997; 9:79-87. [PubMed: 9090498]

43. Hattinger CM, Stoico G, Michelacci F, Pasello M, Scionti I, Remondini D, et al. Mechanisms of gene amplification and evidence of coamplification in drug-resistant human osteosarcoma cell lines. Genes Chromosomes Cancer. 2009; 48:289-309. [PubMed: 19105235]

44. Garzon R, Calin GA, Croce CM. MicroRNAs in Cancer. Ann Rev Med. 2009; 60:167-179. [PubMed: 19630570]

45. Adams J, Kauffman M. Development of the proteasome inhibitor Velcade (Bortezomib). Cancer Invest. 2004; 22:304-311. [PubMed: 15199612]

46. Liu Y, Lashuel HA, Choi S, Xing X, Case A, Ni J, et al. Discovery of inhibitors that elucidate the role of UCH-L1 activity in the H1299 lung cancer cell line. Chem Biol. 2003; 10:837-846. [PubMed: 14522054]

47. Livak KJ, Schmittgen TD. Analysis of relative gene expression data using real-time quantitative PCR and the 2(-Delta Delta C[T]) method. Methods. 2001; 25:402-408. [PubMed: 11846609]

48. Singh D, Febbo PG, Ross K, Jackson DG, Manola J, Ladd C, et al. Gene expression correlates of clinical prostate cancer behavior. Cancer Cell. 2002; 1:203-209. [PubMed: 12086878] 


\section{SIGNIFICANCE}

The deubiquitinating enzyme USP2a has previously been shown to be oncogenic, overexpressed in almost half of human prostate adenocarcinomas, and prolongs the halflife of targets such as fatty acid synthase, MDM2, and cyclin D1. Here, we highlight a new mechanism by which USP2a enhances MYC levels through the modulation of specific subsets of microRNAs in prostate cancer, suggesting alternative therapeutic strategies for targeting MYC. 
A

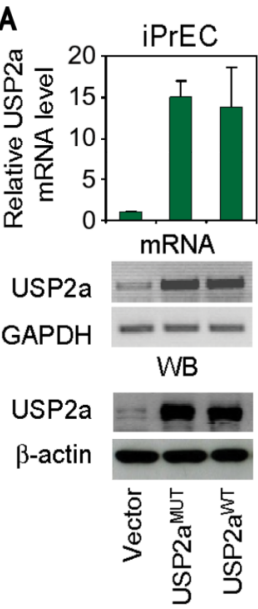

B

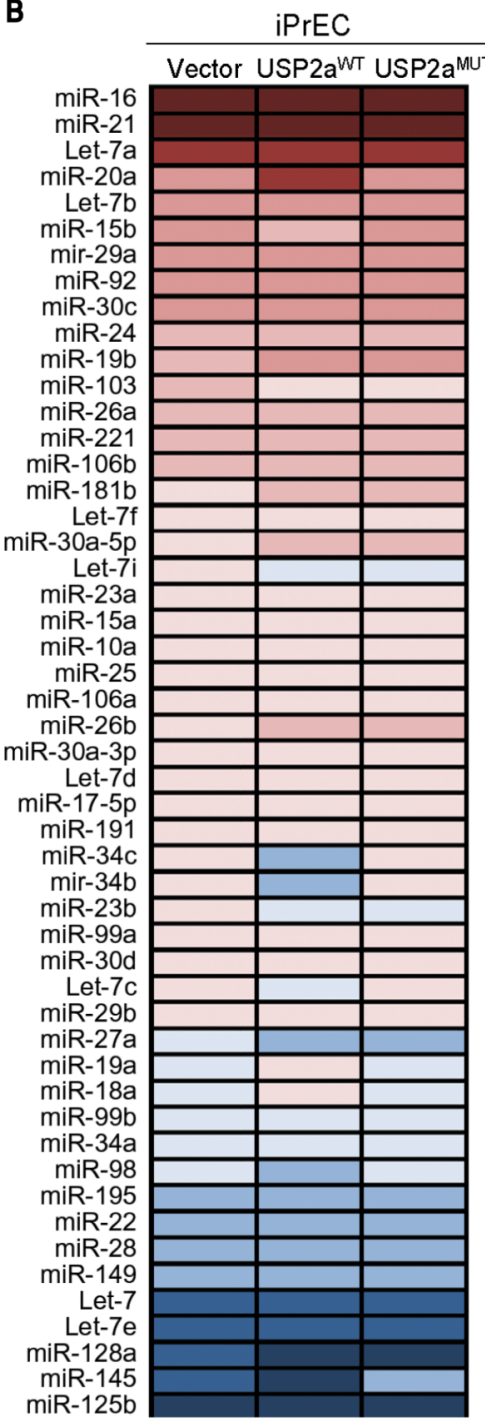

C

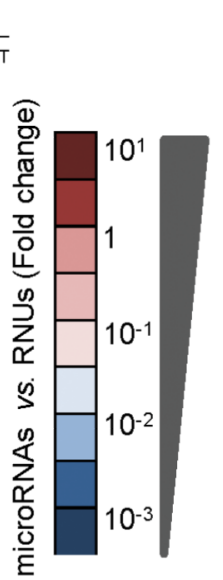

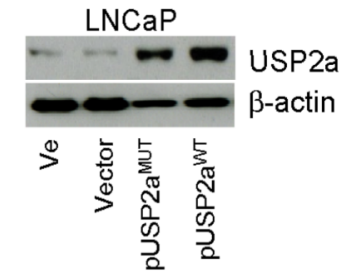

Empty vehicle $(\mathrm{Ve})$

A Vector

pUSP2amUT

- pUSP2a $\mathrm{a}^{\mathrm{WT}}$

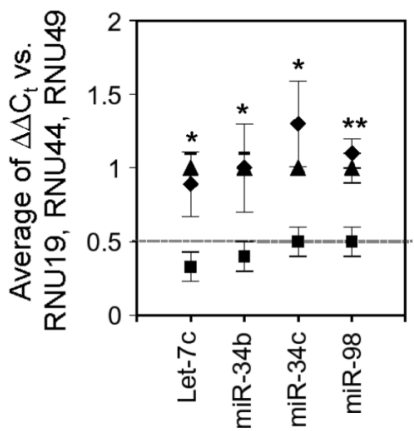

D

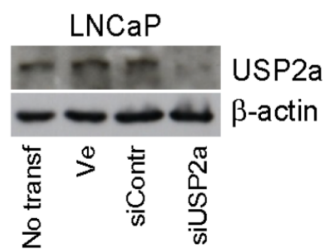

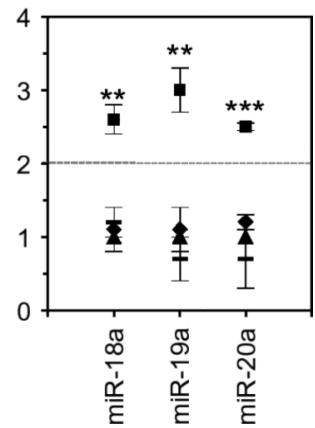

- No transfection

Ampty vehicle (Ve)

- siControl

- siUSP2a
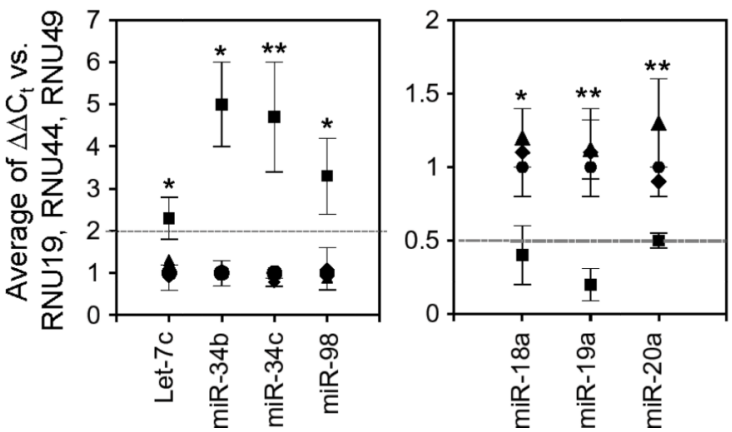

Figure 1.

USP2a overexpression modifies the microRNA expression profile of prostate cells. A, analysis of USP2a mRNA and protein expression in empty vector (Vector), USP2a ${ }^{\text {MUT }}$, and USP2a ${ }^{\text {WT }}$ iPrEC transfectants. B, prostate-specific microRNA expression profiling color heat-map carried out by TaqMan quantitative reverse-transcription PCR assay in the indicated iPrEC cells. Evaluation of USP2a protein expression and microRNA level analysis performed in LNCaP cells on $(\mathbf{C})$ transfection with empty vehicle (Ve), pCDNA3 (Vector), pUSP $2 \mathrm{a}^{\mathrm{MUT}}$, or pUSP2 $\mathrm{a}^{\mathrm{WT}}$; and (D) incubation with empty vehicle (Ve), control (siControl), or specific USP2a (siUSP2a) silencing oligonucleotides. All data represent mean \pm standard deviation of at least three independent replicates. $P$ values: $* P<0.05$, $* * P$ $<0.01, * * * P<0.001$. See also Supplementary Figure S1. GAPDH, glyceraldehyde-3phosphate dehydrogenase; WB, Western blot. 

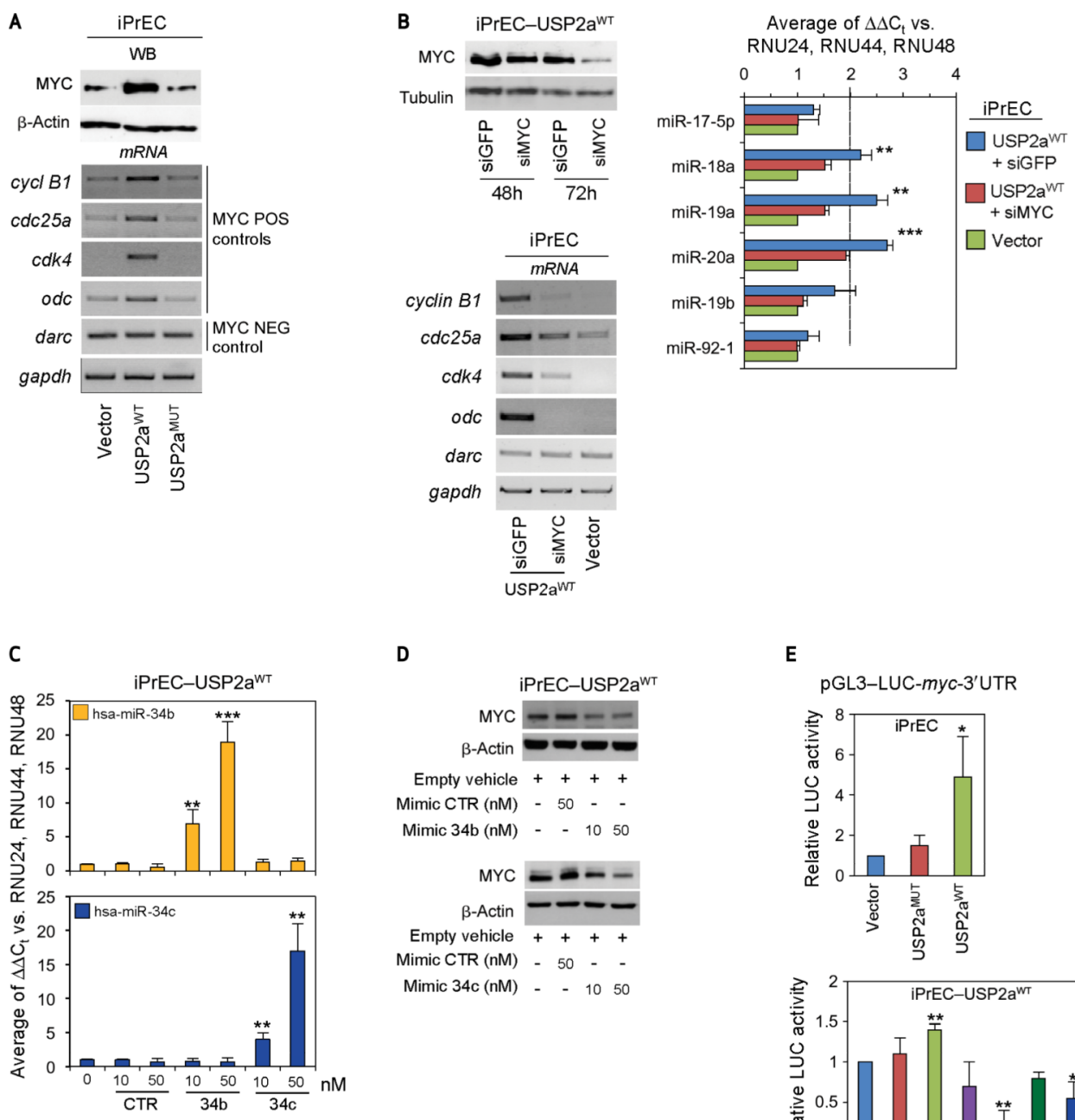

D

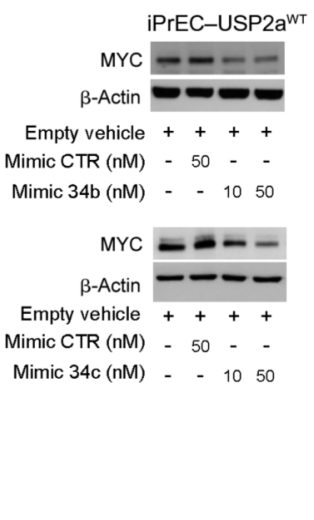

E
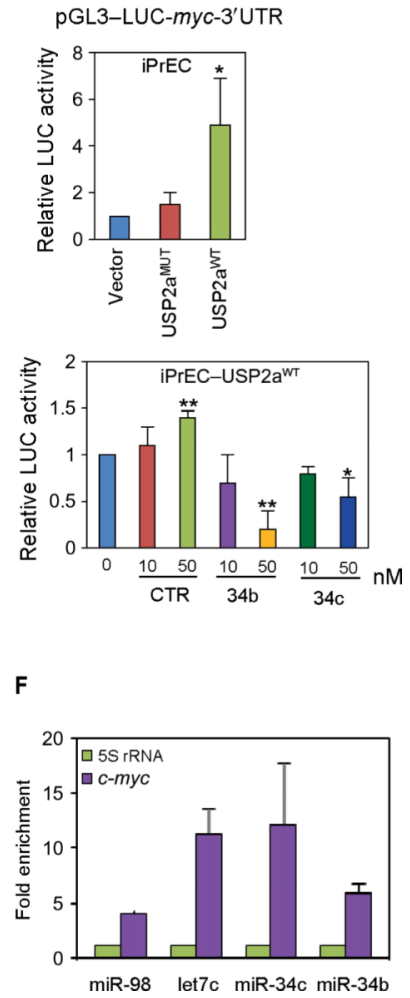

Figure 2.

USP2a-dependent miRs deregulation modulates MYC expression. A, Western blot analysis of MYC protein level and evaluation of MYC specific transcription target genes carried out in USP2a overexpressing immortalized prostate epithelial cells (iPrEC) cells. B, evaluation of MYC protein level (left panel), MYC-regulated transcripts, and microRNAs (right panels) performed in empty vector iPrEC cells (Vector) and iPrEC-USP2aWT cells silenced for either green fluorescent protein or MYC expression. Analysis of miR-34b and miR-34c (C) and MYC expression levels (D) in iPrEC-USP2a ${ }^{\mathrm{WT}}$ cells after treatment with increasing concentrations of control (CTR), miR-34b, and miR-34c synthetic molecules. E, luciferase 
(LUC) reporter assay performed in empty vector (Vector), USP2a ${ }^{\mathrm{MUT}}$, and USP2a ${ }^{\mathrm{WT}}$ iPrEC transfectants (top panel) and in USP2a ${ }^{\mathrm{WT}}$ iPrEC clone exposed to increasing concentrations of control (CTR), miR34b, and miR-34c synthetic molecules (bottom panel). F, isolation of target transcripts associated with miR-34b/c. Cells were cotransfected with expression vectors for HA-tagged AGO1 and the indicated microRNA mimics and a control mimic. The immunoprecipitated RNA was analyzed by qRT-PCR using specific primers for myc and normalized to 5S rRNA and immunoprecipitate from control mimic. miR-98 and let7c, which are known to target $c$-myc, served as controls. Relative to input, $c$-myc was significantly $(P<0.002)$ enriched in the pulldown with miR-34b and miR-34c. All data represent mean \pm standard deviation of at least 3 independent replicates. $P$ values: $* P<0.05$, $* * P<0.01, * * * P<0.001$. See also Supplementary Figures S2 to S5. WB, Western blot. 


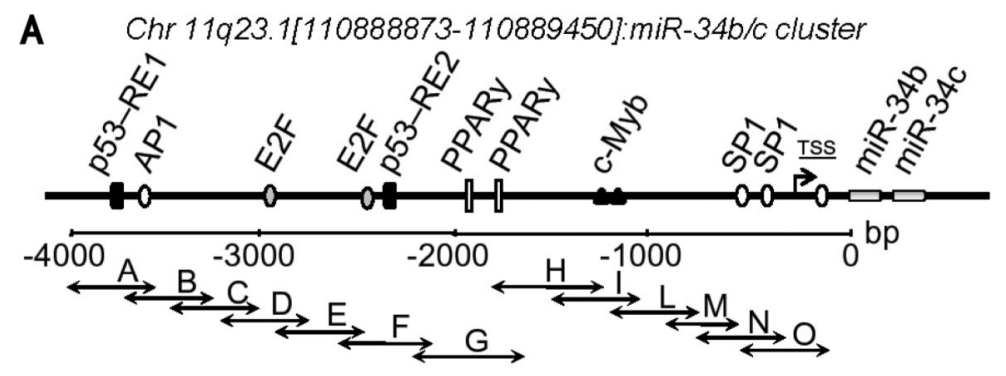

C

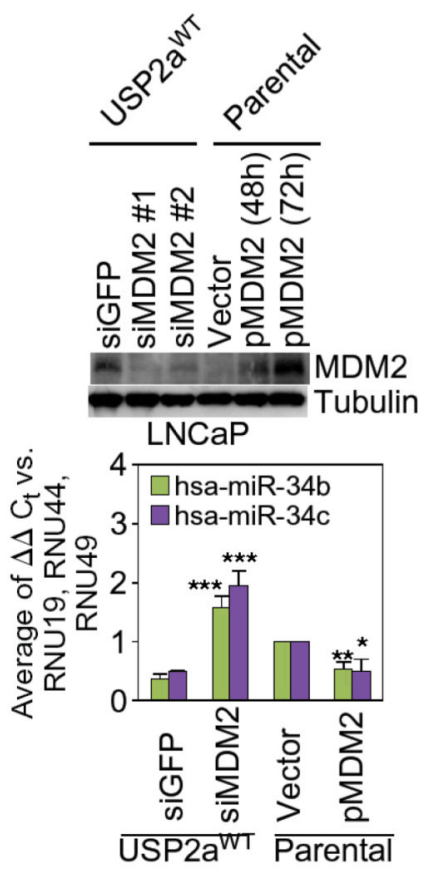

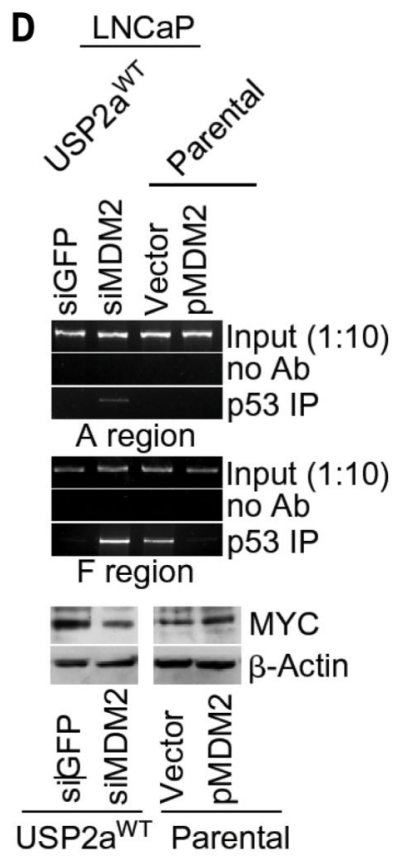
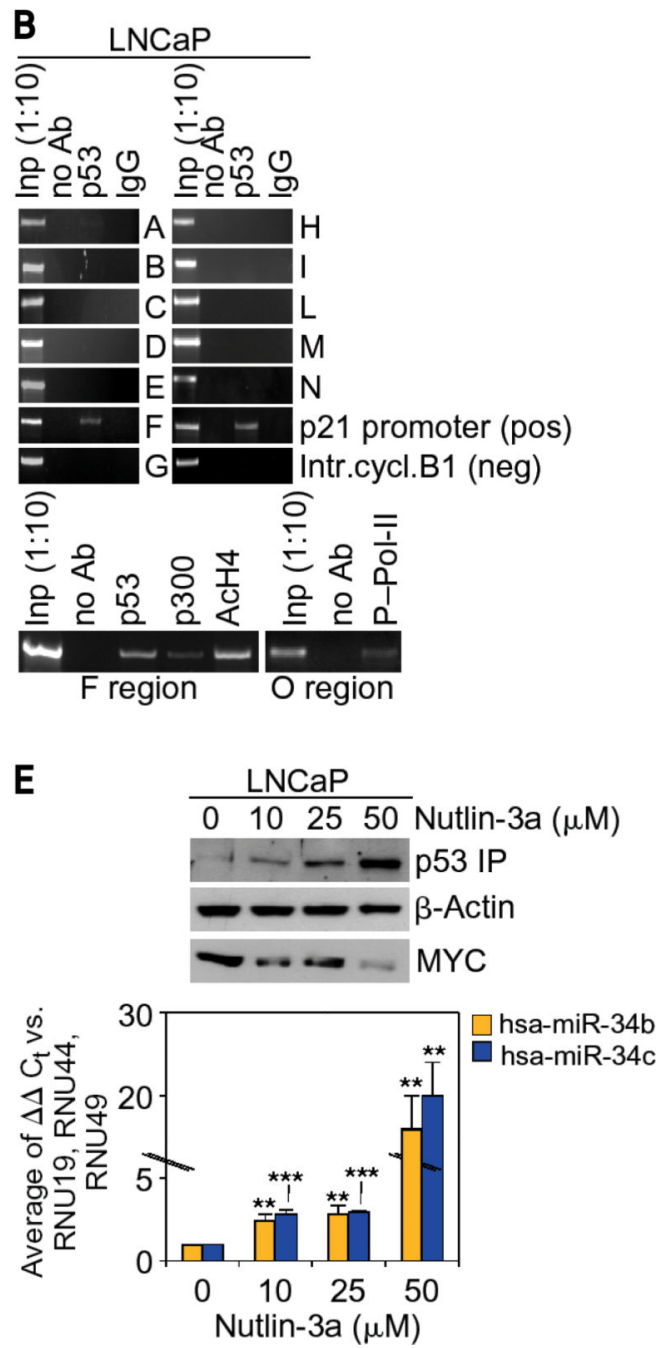

Figure 3.

A, schematic representation of the genomic region mapping $4 \mathrm{~Kb}$ upstream of the miR-34b/c cluster site on chromosome 11 (position 11q23.1: [110,888,873-110,889,450]). DNA fragments amplified by each oligonucleotide pair are represented by arrows (A-O). B, ChIP assay of LNCaP cells with immunoprecipitation of chromatin without antibody (no Ab) and with specific anti-p53, p300, AcH4, phosphorylated Pol-II, or control immunoglobulin G (IgG) antibodies. PCR amplification of amplicons A-O on the putative miR34b/c regulatory region, on the p 21 promoter (positive control), and on the cyclin B1 intron (negative control) are highlighted. C, Western blot evaluation of MDM2 (top panel) and microRNA 34b/c expression analysis (bottom panel) carried out in $\mathrm{LNCaP}$ cells after transient transfection with empty vector (Vector), pMDM2 expression vector, and in USP2aWT_LNCaP transfectants silenced with either control (siGFP) or specific MDM2 siRNAs. D, p53-ChIP assay (as described in B, top panels) and evaluation of MYC protein levels (bottom blots) performed in LNCaP cells after transient transfection with empty vector (Vector), pMDM2 expression vector, and in USP2a ${ }^{\mathrm{WT}}$-LNCaP transfectants silenced with either control (silenced green fluorescent protein) or specific MDM2 siRNAs. E, Western blot of p53 and MYC protein levels (top panel) and miR-34b and miR-34c expression levels (bottom panel) carried out in LNCaP cells treated with increasing concentrations of Nutlin-3a in dimethyl 
sulfoxide. All histograms represent mean \pm standard deviation of at least three independent replicates. $P$ values: $* P<0.05, * * P<0.01, * * * P<0.001$. 

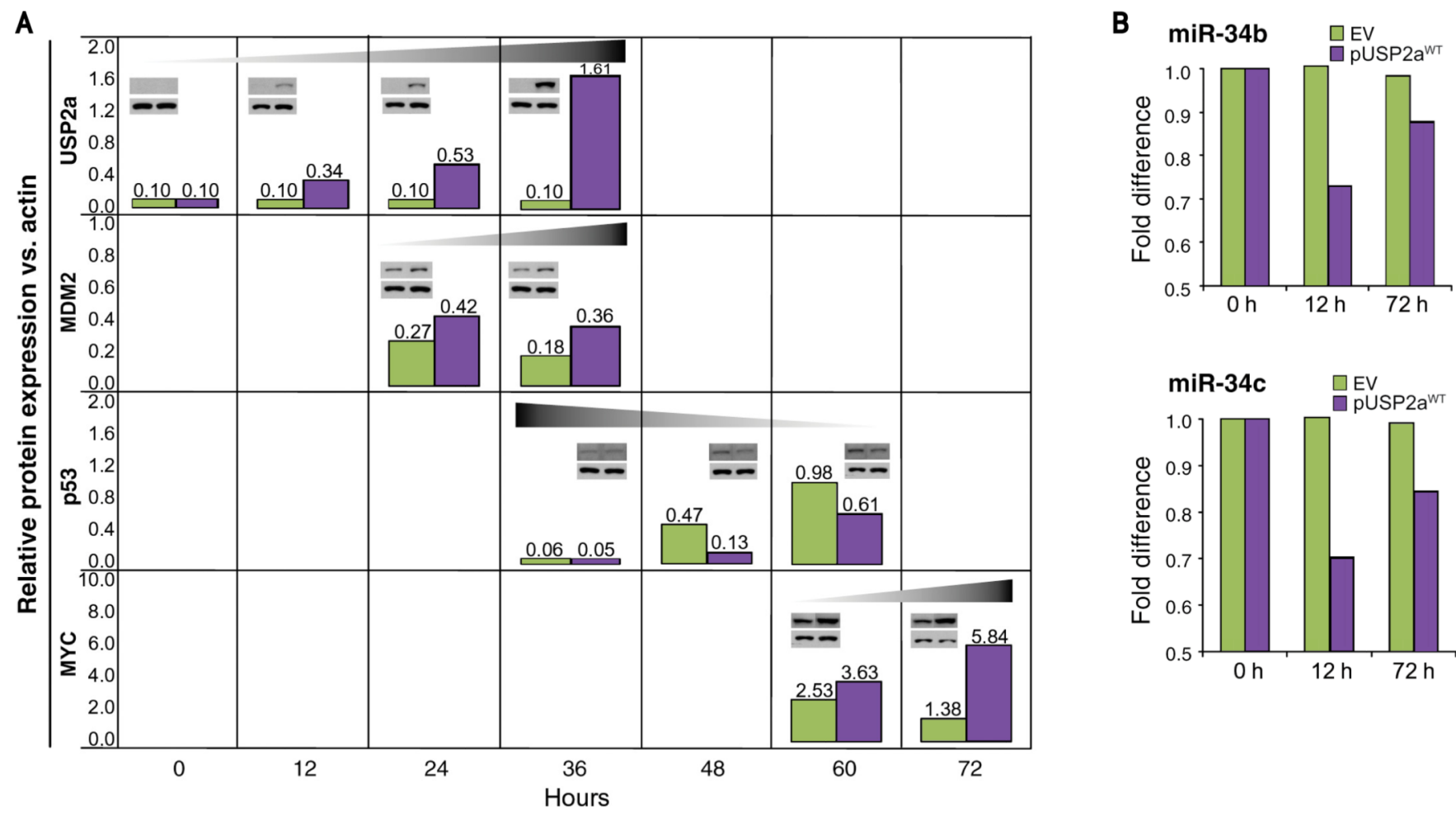

Figure 4.

USP2a regulates MYC expression through the MDM2-p53 axis. A, kinetics profile (0-72 hours) of protein levels in LNCaP cells after pUSP2a ${ }^{\mathrm{WT}}$ (purple bars) overexpression or empty vector (green bars). Representative blots are shown at each set point for the specific protein (upper panel) and actin levels (lower panel). B, miR-34b/c expression profile under the same conditions depicted in A. 
A

Differentially expressed genes (adjusted $P$ value $<0.001$ )

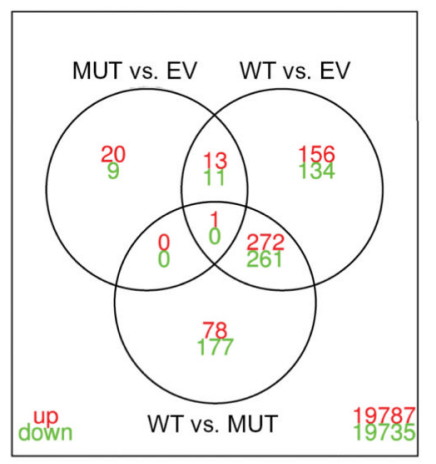

B

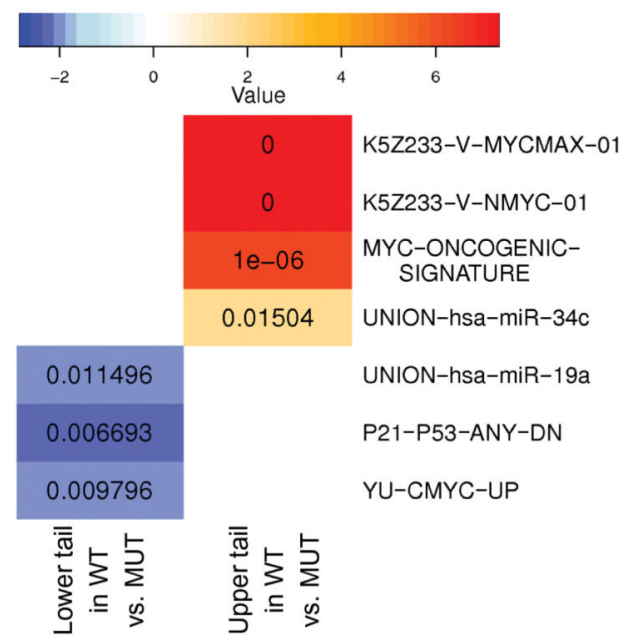

C
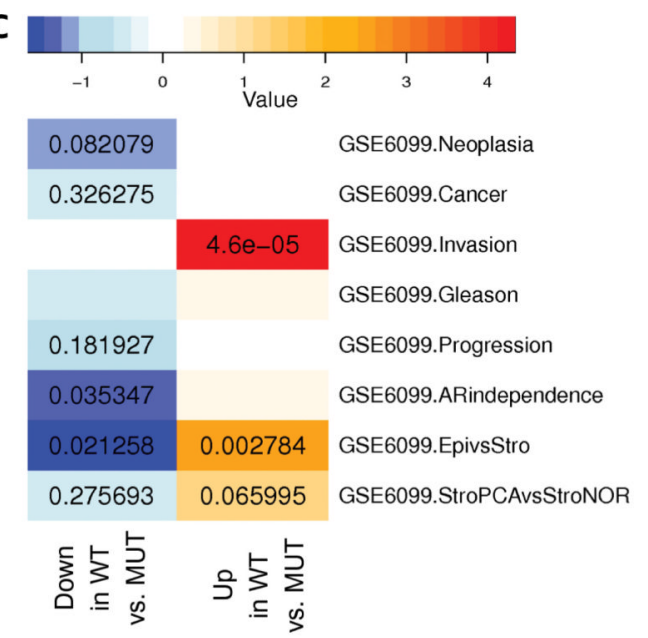

Figure 5.

USP2a overexpression is associated with a discrete mRNA signature that is enriched for MYC-regulated transcripts. A, Venn diagram of differentially expressed genes in immortalized prostate epithelial cells (iPrEC) transfected with USP $2 \mathrm{a}^{\mathrm{WT}}$ and USP $2 \mathrm{a}^{\mathrm{MUT}}$ and empty vector (EV) control. Nominal adjusted $P$ value $<0.0001$; results are for all nonredundant NCBI ENTREZ Gene identifiers available on Affymetrix U133 Plus 2.0 Array. Red, upregulated genes; green, downregulated genes. B, functional annotation analysis for genes differentially expressed between USP $2 \mathrm{a}^{\mathrm{WT}}$ and USP $2 \mathrm{a}^{\mathrm{MUT}}$. Genes were ordered by moderated $t$-statistics obtained from USP $2 \mathrm{a}^{\mathrm{WT}}$ and USP $2 \mathrm{a}^{\mathrm{MUT}}$ contrast, whereas functional gene sets were obtained from different databases (see Supplementary Microarray Methods and Results sections). K5Z233-V-MYCMAX-01 and K5Z233-V-NMYC-01: genes that contain a transcription factor binding site (TFBS) for the heterodimer Myc-Max or $\mathrm{n}-\mathrm{Myc}$ in the $10-\mathrm{Kb}$ genomic region around their transcription starting site (TSS) with a false discovery rate (FDR) less than 1\%; UNION-hsa-miR-34c and UNION-hsa-miR-19a: union sets of genes described as targets for miR-34c or miR19a by DIANA-microT, miRanda, TargetScanS, and PicTar, as obtained from the miRGen database (34); MYCONCOGENIC-SIGNATURE: cMYC target genes (33), functional gene sets obtained from the Molecular Signature Database (MSigDB); P21-P53-ANY-DN: p21 downregulated (p53-dependent) genes (33), functional gene sets from the MSigDB; YU-CMYC-UP: cMyc target genes in a p53-null background, functional gene sets from the MSigDB. Analysis of functional annotation revealed gene set enrichment for upregulation of MYC and miR-34c target genes and gene set enrichment for downregulation of p21-p53 and miR-19a target genes. Color values represent absolute $\log _{10}$ adjusted $P$ values resulting from the Wilcoxon rank-sum test after multiple testing correction. Orange/red boxes show concordant upregulation, whereas blue boxes show concordant downregulation. $\mathbf{C}$, enrichment analysis of genes up- and downregulated in USP $2 \mathrm{a}^{\mathrm{WT}}$ and USP $2 \mathrm{a}^{\mathrm{MUT}}$ in sequential transitions along human prostate cancer progression as analyzed in the GSE6099 data set (36). The following transitions were considered: Neoplasia: prostatic intraepithelial neoplasia epithelial cells versus NORMAL epithelial cells; Cancer: prostatic intraepithelial neoplasia and prostate cancer epithelial cells versus NORMAL epithelial cells; Invasion: prostate cancer epithelial cells versus prostatic intraepithelial neoplasia epithelial cells; Gleason: high Gleason $(<7)$ prostate cancer epithelial cells versus low Gleason $(>7)$ prostate cancer epithelial cells; Progression: metastatic prostate cancer epithelial cells versus locally invasive prostate cancer epithelial cells; AR independence: androgen-resistant metastatic prostate cancer epithelial cells versus androgen-naive metastatic prostate cancer epithelial cells; Epi versus Stro: laser capture-microdissected epithelial cells versus laser capture-microdissected 
stromal cells; Stro prostate cancer versus Stro NOR: laser capture-microdissected from stromal cells adjacent to prostate cancer versus laser capture-microdissected stromal cells from normal prostate. Color values represent absolute $\log _{10} P$ values resulting from the Wilcoxon rank-sum test. Orange/red boxes show concordant upregulation, whereas blue boxes show concordant downregulation. See also Supplementary Figures S9 and S10. 
A
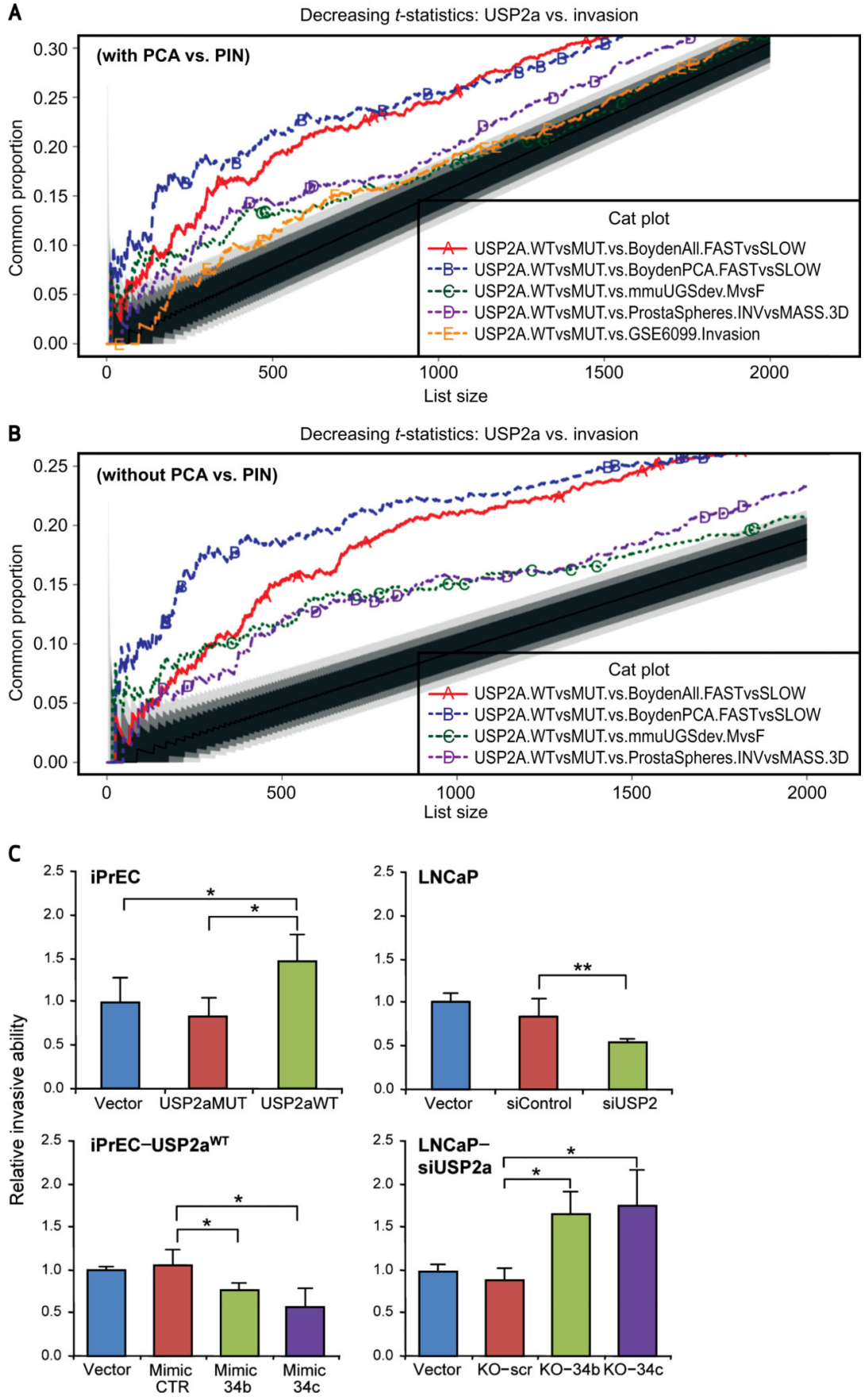

Figure 6.

USP2a overexpression increases the invasive ability of prostate cells. CAT plot showing the agreement between USP2a and invasion gene expression signatures. Genes upregulated by wild-type USP2a transfection as compared with mutant USP2a showed significant overlap with genes expressed on invasion in a number of distinct laboratory models. On the y-axis is shown the proportion of genes in common; on the $\mathrm{x}$-axis is shown the number of top ranking genes considered. The black line corresponds to proportions of common genes by chance; gray shades around this black line correspond to decreasing probabilities of agreement by chance $(0.05,0.01$, and 0.001$)$. Therefore, CAT curves in the top white area of the graph have a probability of agreeing by chance of $P<1 \mathrm{E}-03$. In the figure, genes were ranked by 
decreasing $t$-statistic as obtained from our linear model analysis. Each line represents a different pairwise comparison between differential gene expression between wild-type and mutant USP2a compared with differential gene expression between: A, (A) fast and slow migrating cell lines from various cancer types in Boyden assays (red line); (B) fast (PC3) and slow (LNCaP) migrating prostate cancer (PCA) cell lines in Boyden assays (blue line); (C) mouse male and female urogenital sinuses at gestational day 17 ( \pm 0.5$)$ (green line); (D) Matrigel invasive and noninvasive prostaspheres (purple line); (E) laser capture microdissected epithelial cells from locally invasive prostate cancer and prostatic intraepithelial neoplasia (PIN) (orange line); B, (A) fast and slow migrating cell lines from various cancer types in Boyden assays (red line); (B) fast (PC3) and slow (LNCaP) migrating prostate cancer cell lines in Boyden assays (blue line); (C) mouse male and female urogenital sinuses at gestational day 17 ( \pm 0.5) (green line); (D) Matrigel invasive and noninvasive prostaspheres (purple line); $\mathbf{C}$, evaluation of relative invasive ability performed in iPrEC clones and in LNCaP cells by ECMatrixTM Invasion Chamber. The iPrECUSP2aWT transfectant has been also treated with miR synthetic molecules (mimic), whereas USP2a-silenced LNCaP cells underwent further treatment with specific antagomirs (KO molecules) before invasion assessment. Data represent mean \pm standard deviation of 4 independent replicates. $P$ values: $* P<0.05, * * P<0.01$. 


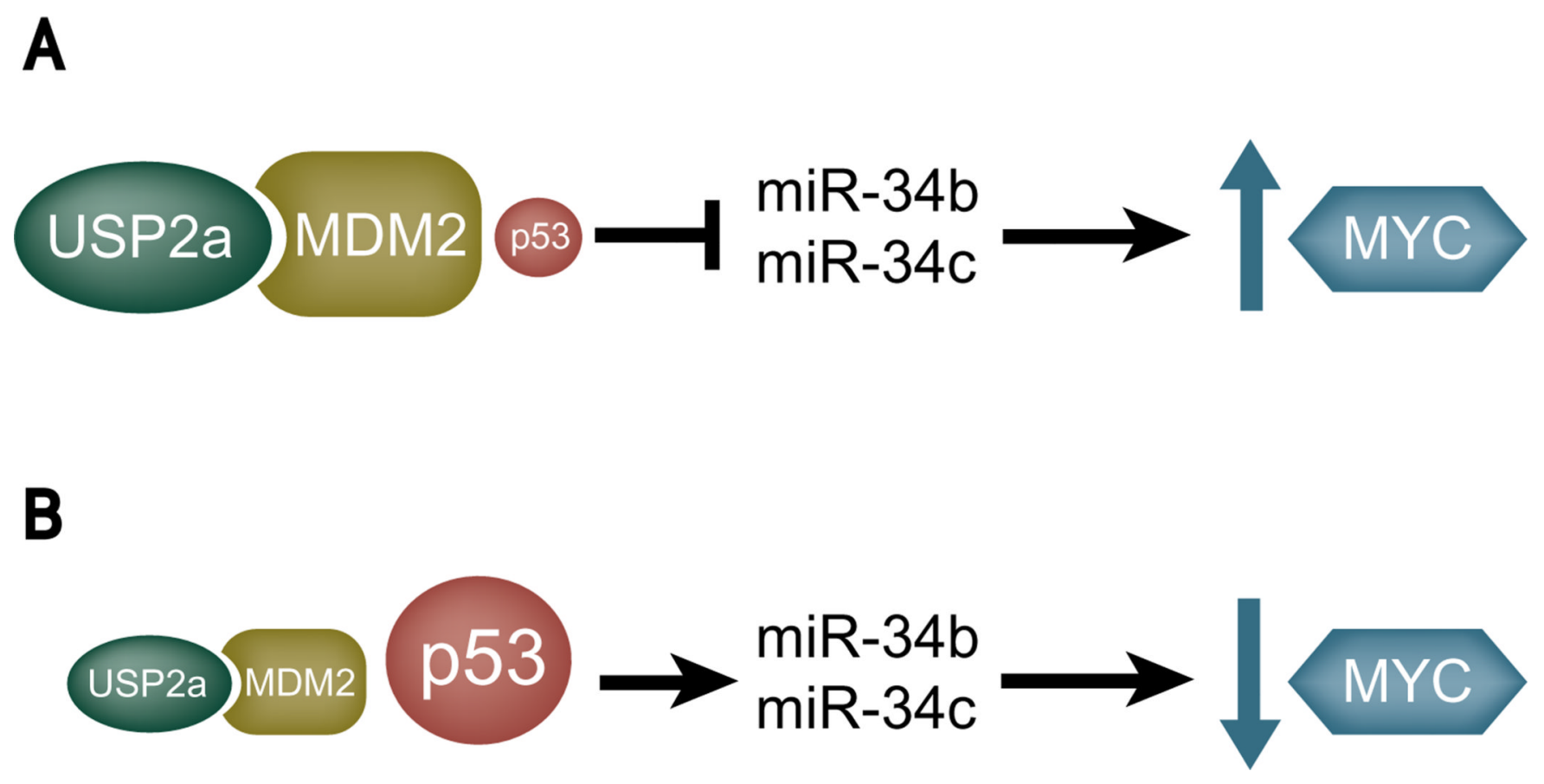

Figure 7.

Proposed model of how USP2a-driven microRNA deregulation enhances MYC protein expression through impairment of the MDM2-p53 pathway. p53 regulates miR-34b/c expression through promoter enhancement. A, when overexpressed, USP2a transcriptionally downregulates miR-34b/c with subsequent MYC activation through MDM2-mediated p53 inactivation. B, low USP2a expression triggers the upregulation of miR-34b/c with subsequent MYC deactivation through MDM2-mediated p53 activation. 